\title{
Integrative analysis of transcriptomics and proteomics of skeletal muscles of the Chinese indigenous Shaziling pig compared with the Yorkshire breed
}

Hu Yang ${ }^{1,2}$, Xing-li X ${ }^{2}$, Hai-ming $\mathrm{Ma}^{1^{*}}$ and Jun Jiang ${ }^{1}$

\begin{abstract}
Background: The Shaziling pig (Sus scrofa) is a well-known indigenous breed in China. One of its main advantages over European breeds is its high meat quality. However, little genetic information is available for the Shaziling pig. To screen for differentially expressed genes and proteins that might be responsible for the meat quality, the longissimus dorsi muscles from Shaziling and Yorkshire pig breeds were investigated using an integrative analysis of transcriptomics and proteomics, involving high-throughput sequencing, the two-dimensional gel electrophoresis, and mass spectrometry.

Results: Sequencing produced 79,320 unigenes by de novo assembly, and 488 differentially expressed genes in the longissimus dorsi muscle of Shaziling pig compared with the Yorkshire breed were identified. Gene Ontology term enrichment of biological functions and Kyoto Encyclopedia of Genes and Genomes analysis showed that the gene products were mainly involved in metabolism, protein binding, and regulation of skeletal muscle development. At the protein level, 23 differentially expressed proteins were identified, which were potentially associated with fatty acid metabolism, the glycolytic pathway, and skeletal muscle growth. Eight differentially expressed genes were confirmed by real-time PCR. These results give an insight into the mechanisms underlying the formation of skeletal muscle in the Shaziling pig.

Conclusions: Certain differentially expressed genes and proteins are involved in fatty acid metabolism, intramuscular fat deposition, and skeletal muscle growth in the Shaziling pig. These results provide candidate genes for improving meat quality and will promote further transcriptomic research in Shaziling pigs.
\end{abstract}

Keywords: Shaziling Pig, RNA-seq, Proteomics, Meat quality

\section{Background}

Pigs are important domestic animals used for meat production worldwide. Pork quality is influenced by many factors, including breed, nutrition, and post-slaughter handling [1]. Among these factors, the breed is the most important. There are more pig breeds in China than in any other country in the word [2]. In China, 118 indigenous pig breeds are listed as the Domestic Animal Diversity in the World index [3]. Over a long period,

\footnotetext{
*Correspondence: mahaiming2000@163.com

${ }^{1}$ College of Animal Science and Technology, Hunan Agricultural University,

Changsha 410128, People's Republic of China

Full list of author information is available at the end of the article
}

breeders have attempted to increase muscle yield and decrease carcass fatness, and great progress for these traits has been made in swine breeding. For example, Landrace pigs and Yorkshire pigs grow more quickly and have higher lean meat than other pig breeds. However, some studies suggest that such intensive selection for increased muscle growth and decreased carcass fatness has led to a deterioration in meat quality [4-6]. Compared with European breeds, Chinese native breeds have higher intramuscular fat (IMF), and increased tenderness and meat quality [7-10]. The Shaziling pig is a well-known breed, which has evolved for centuries in Hunan Province, China, where it feeds on grains, tubers, 
and wild herbs. It is a Chinese fat-type line with high IMF, superior meat quality, and strong resistance to general diseases. Compared with the Shaziling breed, the Yorkshire has a faster growth rate and a leaner meat ratio.

Skeletal muscle contains several fiber types [11]. Muscle fiber types and the proportion of fiber types affect meat quality directly [12]. Therefore, studies on development and growth are beneficial to improve meat quality. Skeletal muscle development is very complicated, and comprises several stages: determination of myoblasts, proliferation of myoblasts, differentiation and fusion of myoblasts into myotubes and myofibers, and growth and maturation $[13,14]$. Analyzing these stages would provide a good basis for understanding muscle fiber development. Previous reports showed that muscle fibers could be classified into red and white fibers [15]. These compositional differences between fibers determine their distinct metabolic type and physiological functions and affect meat quality $[16,17]$. Skeletal muscles have been explored extensively using molecular biology [18, 19], and proteomics and transcriptomics techniques have been applied to study the porcine skeletal muscle of different breeds [20,21].

Over the past decade, proteomic technologies have been used successfully to study skeletal muscle [11, 22]. Proteomic analysis based on two-dimensional gel electrophoresis (2-DE) and mass spectrometry (MS) is a classical method in quantitative proteomics to separate mixtures of proteins into two dimensions and has been a powerful tool in meat science [23, 24]. Many reports concerning differential proteomics among different pig breeds have been published [25-27]. Another technology for characterizing molecular changes in skeletal muscle is analysis of the transcriptome. Recently, transcriptome studies have been applied to analyze differentially expressed genes (DEGs), identify novel genes, describe metabolic pathways, and forecast the relationship between genotypes and phenotypes [28-30]. Next-generation sequencing technology has provided a new tool to quantify transcriptomes and analyze gene expression on a global scale. Transcriptional and proteomic methods could be used to analyze the changes from the mRNA expression to the protein abundance. In addition, post-transcriptional regulation is very important for mRNA stability, translation initiation, and protein stability [31]. Thus, it is necessary to combine proteomic and transcriptional methods simultaneously to analyze skeletal muscle growth and development. Currently, several reports have presented results of both proteomic and transcriptional analyses. For instance, longissimus dorsi muscle (LM) proteome and transcriptome profiles of Yorkshire pig and Casertana pig breeds were compared using 2-DE and a microarray. As a result, a large number of genes were identified that are involved in glycolytic metabolism and skeletal muscle growth [32]. In addition, Kim et al. [33] also compared the LM proteome and transcriptome profiles of different pig breeds using 2-DE and a microarray.

In the present study, we performed transcriptomic and proteomic analyses, along with functional enrichment of Gene Ontology (GO) terms and Kyoto Encyclopedia of Genes and Genomes (KEGG) pathway analysis, to characterize the expression profiles in the LM of Shaziling and Yorkshire pigs. The aim of this study was to reveal the differences in breed-related protein and transcript expression patterns between the two breeds. These results could provide an insight into the mechanisms of growth and development of porcine skeletal muscle.

\section{Methods}

\section{Sample preparation}

Three 25-day-old, male full-sibs for each of Shaziling pigs and Yorkshire pigs were slaughtered following the Animal Care Guidelines of the Ethics committee of Hunan Agricultural University. Samples of LM were collected from the same area of the ribs and placed in liquid nitrogen immediately. All samples were kept at $-80^{\circ} \mathrm{C}$ after collection until used.

\section{Protein extraction}

The frozen LM tissues (100 mg) from Shaziling pigs and Yorkshire pigs were crushed in a mortar containing liquid nitrogen and were then sonicated for $10 \mathrm{~s}$ using a Sonoplus (Bandelin Electronic, Berlin Germany). The crushed tissue was homogenized in $1 \mathrm{~mL}$ of cold dissolution buffer containing $7 \mathrm{M}$ urea, $2 \mathrm{M}$ thiourea, $1 \%$ dithiothreitol (DTT), $4 \%$ (w/v) CHAPS, $20 \mu \mathrm{L}$ protease inhibitor cocktail (BBI, Canada), and $2 \%(\mathrm{v} / \mathrm{v})$ pharmalyte ( $\mathrm{pH} 3-10$; BioRad, Hercules, CA, USA). The homogenate was centrifuged at $15,000 \times \mathrm{g}$, for $20 \mathrm{~min}$ at $4{ }^{\circ} \mathrm{C}$. The supernatant fraction was filtered and kept at $-80{ }^{\circ} \mathrm{C}$ for subsequent analysis. The total protein content was determined using a Bradford assay kit (Bio-Rad).

\section{2-DE and images analysis of gel}

Approximately $100 \mu \mathrm{g}$ of extracted protein was diluted with rehydration buffer [ $8 \mathrm{M}$ urea, $2 \mathrm{M}$ thiourea, $50 \mathrm{mM}$ DTT, $4 \%(\mathrm{w} / \mathrm{v})$ CHAPS, and $0.5 \%$ carrier ampholytes ( $\mathrm{pH} 3-10$, Bio-Rad)]. The mix was loaded onto 13-cm, nonlinear, immobilized $\mathrm{pH}$ gradient strips (IPG, $\mathrm{pH} 3-10$; BioRad), which were rehydrated overnight. After rehydration, first-dimension isoelectric focusing was carried out at $20{ }^{\circ} \mathrm{C}$ at $30 \mathrm{~V}$ for $12 \mathrm{~h}, 500 \mathrm{~V}$ for $1 \mathrm{~h}, 1000 \mathrm{~V}$ for $1 \mathrm{~h}$, and then gradually increased to $8,000 \mathrm{~V}$. Isoelectric focusing was performed using an Ettan IPGphor III system (GE Healthcare, USA) gel apparatus. The focused IPG strips were incubated for $15 \mathrm{~min}$ in equilibration buffer containing $6 \mathrm{M}$ urea, $50 \mathrm{mM}$ Tris- $\mathrm{HCl}, \mathrm{pH} 8.8$, $30 \%$ glycerol, $2 \%$ sodium dodecyl sulfate (SDS), and $1 \%$ DTT. Then, strips were then incubated again for 
$15 \mathrm{~min}$ in a buffer containing $6 \mathrm{M}$ urea, $50 \mathrm{mM}$ Tris- $\mathrm{HCl}$, pH 8.8, 2 \% SDS, 30 \% glycerol, and $4 \%$ iodoacetamide. In the second dimension, the equilibrated IPG strips were placed onto SDS polyacrylamide gels (12.5\% T, $2.6 \% \mathrm{C})$ for protein separation using the Ettan DALT six electrophoresis system (GE Healthcare). When the bromophenol blue dye front reached the bottom of the gel, electrophoresis was stopped and analytical gels were subjected to silver staining and Coomassie blue was used to stain preparative gels before identification by MS. Each sample was analyzed in triplicate.

\section{Spot choosing and tryptic digestion}

Gel images were scanned using an Image Scanner UMax Powerlook 2110XL (GE Amersham) and analyzed using Image Master 2D Platinum software Hofer SE 600 (Version 5.0; GE Amersham). The protein spots were compared automatically using the software, including matching and quality. Spots whose average density was different by more than 1.5-fold between the two pig breeds were analyzed and marked. The differentially abundant spots were cut out from the preparative gel carefully and washed twice with $200 \mu \mathrm{L}$ of $50 \mathrm{mM}$ ammonium bicarbonate with $50 \%$ acetonitrile and incubated for $15 \mathrm{~min}$ at room temperature. The gel pieces were swollen in a digestion solution containing $5 \mu \mathrm{L}$ of $25 \mathrm{mM}$ ammonium bicarbonate and $10 \mathrm{ng}$ of trypsin at $4{ }^{\circ} \mathrm{C}$ for $30 \mathrm{~min}$; in-gel tryptic digestion was run overnight at $37{ }^{\circ} \mathrm{C}$. Subsequently, the supernatant was extracted twice with solvent A ( $80 \%$ acetonitrile, $0.1 \%$ trifluoroacetic acid) for $15 \mathrm{~min}$ at $3{ }^{\circ} \mathrm{C}$. Finally, the digested tryptic peptides were passed through a Zip-Tip to remove salts, according to the manufacturer's protocol.

\section{Mass spectrometry}

The samples were stored at $-70{ }^{\circ} \mathrm{C}$ before analysis by MALDI-TOF/TOF. Protein identification was performed using a 5800 MALDI-TOF/TOF mass spectrometer (AB SCIEX) according to the manufacturer's instructions. Mass spectra were acquired in reflector mode, and recorded in the range of 800-4,500 Da. Eight of the most intense ion signals were selected as precursors for the acquisition of MS/MS. The resulting peptide masses were submitted into the database of the National Center for Biotechnology Information non-redundant (NCBI nr) and the Swiss-Prot database using the Mascot server (Matrix Science, London, UK) to identify proteins. The search parameters were set at $\pm 100 \mathrm{ppm}$ for peptidemass mapping (PMF), peptide tolerance and \pm 0.4 Da for the MS/MS tolerance.

\section{RNA isolation and transcriptome analysis}

Total RNA was extracted from the LM of the two breeds of the pig using the total RNA extraction kit
(Qiagen, Valencia, CA, USA), in accordance with the manufacturer's instructions. The RNA quantity and integrity were checked using a NanoDrop 2000 spectrophotometer and bioanalyzer 2100 (Agilent Technologies, Santa Clara, CA, USA). A TruSeq RNA Sample Preparation kit v2 (Illumina, San Diego, CA, USA) was used to construct cDNA libraries. Subsequently, the libraries were sequenced using an Illumina HiSeq 2500 instrument (Illumina, San Diego, CA, USA) that generated pairedend reads of $100 \mathrm{bp}$.

\section{De novo assembling and functional annotation of reads}

Raw sequencing reads of each sample were trimmed and assembled de novo using CLC Genomics Workbench (CLC Bio, Aarhus, Denmark). After the adapter sequences, ambiguous bases and sequences less than 20 nucleotides were removed, credible contigs generated by de novo sequence assembly. The assembled contigs were annotated against the UniProt and NCBI non-redundant (nr) database using BlastX alignment with an E-value cut off of $<1 \mathrm{e}-5$. Based on the annotation results, GO terms were extracted using Blast2GO (http://www.blast2go.com) and the results were classified as biological processes, cellular components, and molecular functions. The EuKaryotic Orthologous Groups (KOG) and KEGG databases were used to predict the functions and define the main metabolic pathways, separately.

\section{Gene expression quantification and differential expression analysis}

The expression level of each gene was calculated using the reads per $\mathrm{kb}$ per million reads values by the Qualimap v0.5 software [34]. The DEGseq program [35] and R packages were used to identify significantly DEGs between Shaziling pigs and Yorkshire pigs. In this study, the criteria were a fold change (FC) greater than two and cut-off of the false discovery rate of $5 \%$. For the unigenes that were considered as having differential expression, GO functional enrichment was carried out when the $P$ value was less than 0.05. DEGseq provides statistical routines for determining DEGs.

\section{Validation of DEGs by quantitative real-time PCR (qPCR)}

To validate the expression level of the DEGs, eight DEGs from 2-DE results were analyzed by using qPCR. These genes included Enolase 3 (ENO3); ATP synthase subunit beta, mitochondrial (ATP5B); Enolase 1 (ENO1); Triosephosphate Isomerase (TPI); alpha-actin (ACTA1); actin, alpha, cardiac muscle 1 (ACTC1); myosin light chain, phosphorylatable, fast skeletal muscle (MYLPF); and heat shock protein 27 (HSPB1), which mainly belonged to metabolic pathways and structural proteins. Total RNA was extracted from the LM of Shaziling and Yorkshire pigs using the Trizol reagent (Invitrogen, CA, USA), 
according to the manufacturer's instructions, and the RNA was treated with RNase-free DNase (Qiagen, Valencia, CA, USA). The quality and concentration of the total RNA was evaluated by gel electrophoresis. The cDNA synthesis of samples was performed using the Quantitect Reverse Transcription kit (Qiagen). The primers (Table 1) were designed by the Roche Universal Probe Library Assay Design Center (https://www.roche-applied-science.com) and synthesized by Sangon Biotechnology Corporation (Shanghai, China). qPCR was performed on an Applied Biosystems 7300 Real time PCR system (Applied Biosystems, USA) with the SYBR Premix Ex Taq Kit (Takara Biotechnology, Japan) in a $20-\mu \mathrm{L}$ PCR mix. GAPDH was used as the reference gene to measure the expression levels of mRNA between the samples and data were calculated by the $2^{-\Delta \Delta C t}$ comparative CT method [36].

\section{Results and discussion}

\section{Identification of differentially abundant proteins by} 2-DE and MS

The Longissimus dorsi proteomes from the two pig breeds were analyzed by the 2-DE technique. Thirtyeight protein spots (Fig. 1) were significantly different (FC >1.5) between the two breeds: 27 protein spots were upregulated in Shaziling pigs and 11 in Yorkshire. The differentially abundant protein spots were identified by MALDI-TOF/TOF-MS: two spots could not be identified successfully; however, the 36 remaining spots were identified by matching peptide data to the UniProt database. The characteristics of the identified proteins and the identification parameters are listed in Table 2. Some of the identified proteins were resolved as multiple spots. For example, spots 2480, 2654, and 2659 represented the same protein and showed similar quantitative trends. Ultimately, 23 different proteins were identified.

\section{Function analysis of differentially expressed proteins}

To further determine the functions of the differentially abundant proteins, functional categorization of all the identified proteins was performed using GO annotation. The annotated results of biological process are shown in Fig. 2. The 23 differential proteins were grouped into 11 categories. We focused on the categories of fatty acid metabolism, glycolytic pathway, and skeletal muscle growth and development. The result of enrichment analysis revealed that some of the identified proteins had an important impact on meat quality. For example, TPI plays an important role in ensuring immediate equilibration of the triosephosphates produced by aldolase in glycolysis, which is interconnected with lipid metabolism and to the pentose phosphate pathway [37]. In addition, a previous report showed that a quantitative increase in TPI was positively correlated with more tender meat [38].

Enolase 3 was another metabolic enzyme that was differentially abundant between the two breeds. Enolase 3 is a crucial enzyme in glycolysis that catalyzes the interconversion of diphosphoglycerate and phosphoenolpyruvate. Pig muscle Enolase 3 was investigated some time ago [39]. Many isoforms of Enolase 3 have been confirmed to have an influence on IMF in pigs [20,40].

Muscles are composed primarily of different muscle fibers. Muscle fiber type is an important factor influencing meat quality [41]. For example, increasing the percentage of type IIb fibers could lead to the reduced meat quality because of altered metabolic rates and biochemical processes [42]. ACTA1 is a member of the actin family and is a major constituent of the contractile apparatus in skeletal

Table 1 Primer sequences for the quantitative real-time PCR amplification of the differential expressed genes in Shaziling and Yorkshire pigs

\begin{tabular}{|c|c|c|c|}
\hline Genes & Primer sequences $\left(5^{\prime}-3^{\prime}\right)$ & Product size & GenBank sequence no. \\
\hline HSPB1 & $\begin{array}{l}\text { F: CGGCAGGATGAGCACGGCTTCA } \\
\text { R: GCGCCTCGAAAGTGACAGGGATGG }\end{array}$ & $184 \mathrm{bp}$ & gi|55926209 \\
\hline ENO1 & $\begin{array}{l}\text { F: GGGGCCTCAACTGGGATCTACGA } \\
\text { R: TCCGTGCCGTCCATCTCAATCA }\end{array}$ & $191 \mathrm{bp}$ & gi|753703906 \\
\hline ATP5B & $\begin{array}{l}\text { F: CCCTTCTGCGGTGGGTTAT } \\
\text { R: CACGGGACAGCACAGTGGTAG }\end{array}$ & $188 \mathrm{bp}$ & gi|89574051 \\
\hline TPI1 & $\begin{array}{l}\text { F: CAGAGCACCCGCATCATTTACG } \\
\text { R: AAGCGCCACCCACAAGGAAC }\end{array}$ & $100 \mathrm{bp}$ & gi|262263205 \\
\hline ACTC1 & $\begin{array}{l}\text { F: GGGGATGGCGTAACCCACA } \\
\text { R: GGCAAGGCATAGCCCTCGTAA }\end{array}$ & $50 \mathrm{bp}$ & gi|545801458 \\
\hline MYLPF & $\begin{array}{l}\text { F: GGCGGCAACGTGGACTACAA } \\
\text { R: GGCCATCAAAGACCGAAGAGG }\end{array}$ & $94 \mathrm{bp}$ & gi|117660856 \\
\hline ENO3 & $\begin{array}{l}\text { F: CGGGAAGGACGCCACCAAT } \\
\text { R: CCGTTGCGGTAGAACTCAGATGC }\end{array}$ & $165 \mathrm{bp}$ & gi|113205498 \\
\hline ACTA1 & $\begin{array}{l}\text { F: TCAGGAAGGACCTGTATGCCAACAA } \\
\text { R: TGGACAGCGAGGCCAGGATG }\end{array}$ & $186 \mathrm{bp}$ & gi|268607671 \\
\hline
\end{tabular}




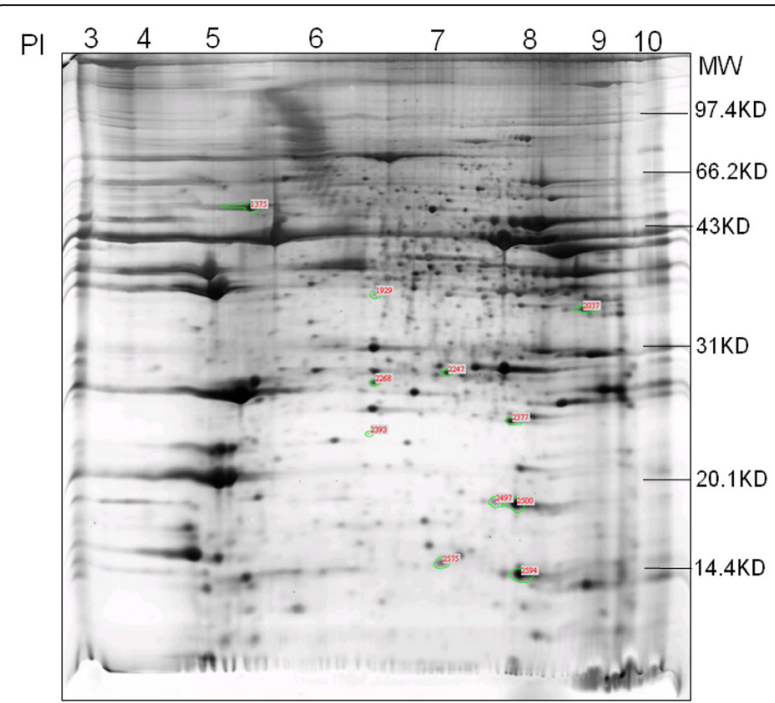

a

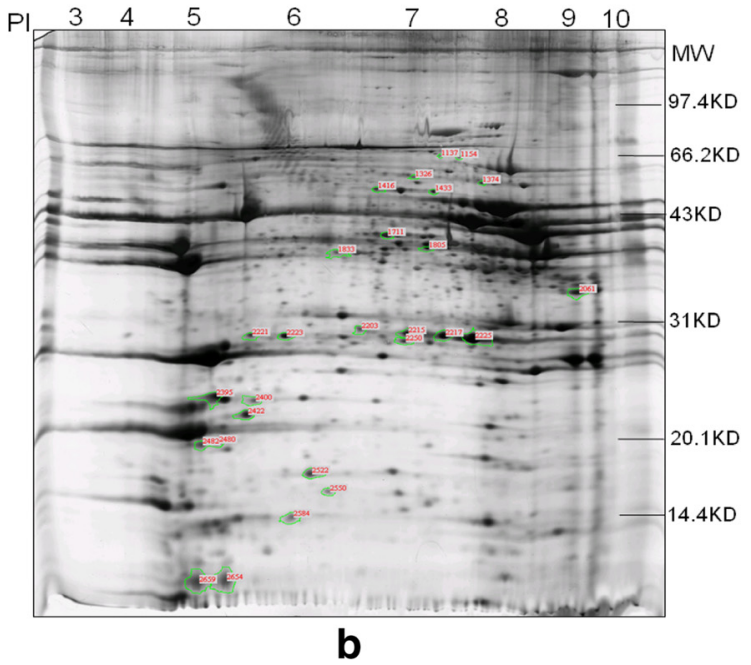

Fig. 1 2-DE map of longissimus dorsi musle from Yorkshire and Shaziling pig breeds. Scanned 2-DE image of separated using an IPG pH 3-10 strip in the first dimension (12 cm, BioRad, USA), and $12.5 \%$ SDS gel in the second dimension. Tag show 38 spots that were significantly changed between the two breeds [a Yorkshire pigs (up-regulation), b Shaziling pigs (up-regulation)]

muscle. Previous reports showed that alpha-actin levels positively correlate with the synthesis of muscle fiber proteins and muscle growth [43]. In this study, ACTA1 was differentially abundant between the two pig breeds.

Heat shock proteins (HSPs) including HSPA1, HSPA8, HSPB1, and other chaperone proteins have been associated with pig meat quality $[44,45]$. In the present study, HSPB1 was more abundant in the Shaziling pig compared with the Yorkshire pig. This observation suggested that HSPB1 is correlated with meat quality. In addition to tenderness, further research is needed to confirm whether the IMF content of meat is affected by the expression of HSPB1.

\section{Illumina sequencing and de novo assembly}

Sequencing generated 30,751,992 and 35,933,274 100-bp paired-end reads from cDNA libraries of Shaziling and Yorkshire pigs, respectively. After trimming of low-quality reads and the removal of adapters, 29,522,984 and $34,937,710$ reads were used for de novo assembly. The reads were assembled into 86,759 contigs (N50=939 bp) ranging from 100 to $49,881 \mathrm{bp}$, with an average length of $672 \mathrm{bp}$. Thereafter, the contigs were assembled into scaffolds (N50 = $1028 \mathrm{bp}$ ) with a mean length of $713 \mathrm{bp}$. After the final assembly of scaffolds using CAP3 [46], we obtained 79,320 unigenes $(\mathrm{N} 50=1112 \mathrm{bp})$ with an average length of $733 \mathrm{bp}$ and a maximum of $66,767 \mathrm{bp}$. The length distribution of the assembled unigenes is shown in Fig. 3. The result of the assembly is shown in Table 3. The transcriptome data have been submitted to the NCBI GEO database under accession number GSE70673.

\section{Functional annotation of longissimus dorsi transcripts}

To validate and annotate the protein functions of the 79,320 assembled unigenes, they were searched against the NCBI $\mathrm{nr}$ and UniProt protein database using the BLAST program (E-value cutoff $<1 \mathrm{e}^{-5}$ ). Of the 79,320 assembled unigenes, 23,055 sequences (29.07\%) were assigned to the $\mathrm{nr}$ database, and 25,784 sequences $(32.50 \%)$ were found to have significant similarity with proteins in the UniProt database (Table 4). Approximately $30 \%$ of all assembled unigenes was perfectly matched to the Uniprot database and the nr database, respectively. Thus, most of the assembled unigenes were unknown, indicating that many new genes and non-coding RNA sequences were obtained. Generally, direct sequencing of transcriptomes is considered an effective tool to discover new genes $[47,48]$ and has been applied to various organisms $[49,50]$. These unigenes provided much valuable information for further identification of genes related to development of the longissimus dorsi.

\section{Functional classification of unigenes}

$\mathrm{GO}$ is an extremely useful tool to classify the functions of a large quantity of genes, and is an international standardized gene functional classification system. GO analysis has been widely applied to predict the functions of genes in many organisms. Three ontologies, cellular component, molecular function, and biological process, are shared in the GO database. In this study, of the annotated unigenes, 23,702 could be assigned to the biological process (BP, 111,204 sequences), cellular components (CC, 68,072), and molecular functions (MF, 30,087) (Fig. 4) using the Blast2GO program [51]. In the biological process, the majority of unigenes were involved in catalytic activity and transcription factor activity, indicating that they might play a key role in the regulation of skeletal muscle development. In cellular components, organelle, 
Table 2 Protein differentially expressed for Shaziling pig breeds and Yorkshire were identified by 2-DE and MALDI-TOF-MS/MS

\begin{tabular}{|c|c|c|c|c|c|c|c|c|}
\hline Sport no & $\begin{array}{l}\text { NCBI accession } \\
\text { number }\end{array}$ & Protein name & $\begin{array}{l}\mathrm{Mr}, \mathrm{kDa} \\
\text { theor }\end{array}$ & pl theor & $\begin{array}{l}\text { No. of peptides } \\
\text { identified }\end{array}$ & Mascot score & $\begin{array}{l}\text { Sequence } \\
\text { coverage }\end{array}$ & Expect $^{e}$ \\
\hline \multicolumn{9}{|c|}{ Up-regulated in Yorkshire pigs } \\
\hline 1375 & gi|89574051 & $\begin{array}{l}\text { mitochondrial ATP synthase, } \\
\mathrm{H}^{+} \text {transporting F1 complex } \\
\text { beta subunit, partial, ATP5B }\end{array}$ & 47059.6 & 4.99 & 16 & 1180 & $46 \%$ & $5.8 \mathrm{e}-11$ \\
\hline 1929 & gi|283993079 & L-gulonate3-dehydrogenase & 35433.2 & 5.79 & 14 & 417 & $51 \%$ & $1.2 \mathrm{e}-03$ \\
\hline 2268 & gi|545835136 & $\begin{array}{l}\text { PREDICTED: NADH } \\
\text { dehydrogenase ubiquinone } \\
\text { flavoprotein } 2 \text { isoform X1 }\end{array}$ & 25812.2 & 6.96 & 14 & 435 & $60 \%$ & $1.8 \mathrm{e}-039$ \\
\hline 2247 & gi|55926209 & heat shock protein beta-1 & 22984.7 & 6.23 & 9 & 423 & $41 \%$ & $2.9 e-03$ \\
\hline 2393 & gi|809283 & $\begin{array}{l}\text { Chain B, Structure Determination } \\
\text { Of Aquomet Porcine Hemoglobin } \\
\text { At } 2.8 \text { Angstrom Resolution }\end{array}$ & 16082.4 & 6.76 & 12 & 511 & $86 \%$ & 4.6e-04 \\
\hline 2377 & gi|545848507 & $\begin{array}{l}\text { PREDICTED: alpha-crystallin B chain } \\
\text { isoform X2 }\end{array}$ & 20116.4 & 6.76 & 9 & 212 & $51 \%$ & $3.7 e-01$ \\
\hline 2497 & gi|494389 & $\begin{array}{l}\text { Chain A, High Resolution X-Ray } \\
\text { Structures Of Pig Metmyoglobin }\end{array}$ & 16901.8 & 6.5 & 9 & 529 & $59 \%$ & $7.3 e-04$ \\
\hline 2500 & gi|494389 & $\begin{array}{l}\text { Chain A, High Resolution X-Ray } \\
\text { Structures Of Pig Metmyoglobin }\end{array}$ & 16901.8 & 6.5 & 12 & 596 & $82 \%$ & $1.5 e-05$ \\
\hline 2575 & gi|55926217 & $\begin{array}{l}\text { cytochrome c oxidase subunit } 5 B \text {, } \\
\text { mitochondrial precursor }\end{array}$ & 14002 & 8.8 & 8 & 334 & $46 \%$ & $2.3 e-02$ \\
\hline 2594 & gi|809283 & $\begin{array}{l}\text { Chain B, Structure Determination } \\
\text { Of Aquomet Porcine Hemoglobin } \\
\text { At } 2.8 \text { Angstrom Resolution }\end{array}$ & 16082.4 & 6.76 & 9 & 400 & $67 \%$ & $5.8 \mathrm{e}-03$ \\
\hline \multicolumn{9}{|c|}{ Up-regulated in Shaziling pigs } \\
\hline 2480 & gi|117660856 & MYLPF & 19.0 & 4.8 & 6 & 110 & $36 \%$ & $5.8 \mathrm{e}-00$ \\
\hline 2395 & gi|117660874 & MLC1f & 21018.6 & 4.9 & 11 & 444 & $60 \%$ & $2.3 e-40$ \\
\hline 2654 & gi|117660856 & MYLPF & 19066.3 & 4.8 & 9 & 347 & $49 \%$ & $1.2 \mathrm{e}-03$ \\
\hline 2422 & gi|117660890 & MLC3f & 16761.2 & 4.6 & 4 & 250 & $29 \%$ & $2.3 e-02$ \\
\hline 2659 & gi|117660856 & MYLPF & 19066.3 & 4.8 & 6 & 144 & $27 \%$ & $2.3 e-01$ \\
\hline 2400 & gi|545858131 & $\begin{array}{l}\text { keratin, type I cytoskeletal } 10 \\
\text { isoform X2 }\end{array}$ & 58318.6 & 4.9 & 16 & 190 & $21 \%$ & $5.8 \mathrm{e}-01$ \\
\hline 2482 & gi|117660856 & MYLPF & 19066.3 & 4.8 & 16 & 600 & $86 \%$ & $5.8 \mathrm{e}-05$ \\
\hline 2522 & gi|117660874 & MLC1f & 21018.6 & 4.9 & 8 & 190 & $40 \%$ & $5.8 \mathrm{e}-01$ \\
\hline 1154 & gi|545845559 & $\begin{array}{l}\text { PREDICTED: fibrinogen beta } \\
\text { chain isoform } \times 2\end{array}$ & 50399.8 & 7.94 & 18 & gi|545845559 & $43 \%$ & 4.6e-03 \\
\hline 2225 & gi|262263205 & triosephosphate isomerase 1 & 26878.9 & 6.54 & 14 & 463 & $74 \%$ & $2.9 \mathrm{e}-04$ \\
\hline 2203 & gi|262263205 & Triosephosphate somerase 1 & 26878.9 & 6.54 & 17 & 774 & $77 \%$ & $2.3 \mathrm{e}-07$ \\
\hline 1326 & gi|311247991 & $\begin{array}{l}\text { PREDICTED: pyruvate } \\
\text { dehydrogenase protein } \\
\text { Xcomponent-like isoform }\end{array}$ & 54036.4 & 8.3 & 12 & 317 & $28 \%$ & $1.2 \mathrm{e}-02$ \\
\hline 1416 & gi|545801458 & $\begin{array}{l}\text { PREDICTED: actin, alpha } \\
\text { cardiac muscle } 1 \text { isoform } \times 1\end{array}$ & 42334 & 5.2 & 10 & 313 & $31 \%$ & $2.9 \mathrm{e}-02$ \\
\hline 2250 & gi|262263205 & $\begin{array}{l}\text { Triosephosphate isomerase } 1, \\
\text { TPI1 }\end{array}$ & 26878.9 & 6.5 & 17 & 795 & $82 \%$ & $1.8 \mathrm{e}-07$ \\
\hline 2584 & gi|314907119 & $\begin{array}{l}\text { A-FABP adipocyte fatty } \\
\text { acid-binding protein }\end{array}$ & 14780.6 & 6.2 & 8 & 371 & $56 \%$ & 4.6e-03 \\
\hline 1433 & gi|545833443 & $\begin{array}{l}\text { PREDICTED: alpha-enolase } \\
\text { isoform } X 1\end{array}$ & 38172.7 & 8.93 & 12 & 377 & $41 \%$ & $1.2 \mathrm{e}-03$ \\
\hline 2221 & gi|55926209 & HSPB1 heat shock protein & 22984.7 & 6.23 & 8 & 236 & $31 \%$ & $1.5 \mathrm{e}-01$ \\
\hline
\end{tabular}


Table 2 Protein differentially expressed for Shaziling pig breeds and Yorkshire were identified by 2-DE and MALDI-TOF-MS/MS (Continued)

\begin{tabular}{|c|c|c|c|c|c|c|c|c|}
\hline 1805 & gi|545859898 & $\begin{array}{l}\text { PREDICTED: beta-enolase } \\
\text { isoform } \mathrm{X} 1\end{array}$ & 48154.9 & 8.52 & 17 & 414 & $40 \%$ & $2.3 e-03$ \\
\hline 2550 & gi|545805333 & $\begin{array}{l}\text { PREDICTED: } 14 \mathrm{kDa} \\
\text { phosphohistidine phosphatase } \\
\text { isoform X2 }\end{array}$ & 14036.8 & 5.91 & 14 & 454 & $74 \%$ & $2.3 e-04$ \\
\hline 2217 & gi|262263205 & triosephosphate isomerase 1 & 26878.9 & 6.54 & 16 & 701 & $82 \%$ & $4.6 \mathrm{e}-06$ \\
\hline 1711 & gi|46389777 & $\begin{array}{l}\text { troponin T fast skeletal } \\
\text { muscle type }\end{array}$ & 30720.1 & 8.68 & 14 & 423 & $41 \%$ & $2.9 \mathrm{e}-03$ \\
\hline 1137 & gi|545845559 & $\begin{array}{l}\text { PREDICTED: fibrinogen beta } \\
\text { chain isoform } X 2\end{array}$ & 50399.8 & 7.94 & 15 & 289 & $34 \%$ & $7.3 e-02$ \\
\hline 2215 & gi|262263205 & triosephosphate isomerase 1 & 26878.9 & 6.54 & 18 & 684 & $76 \%$ & $2.3 e-06$ \\
\hline 2223 & gi|55926209 & HSPB1 heat shock protein beta- 1 & 22984.7 & 6.23 & 10 & 371 & $42 \%$ & $4.6 \mathrm{e}-03$ \\
\hline 1833 & gi|545832797 & $\begin{array}{l}\text { PREDICTED: troponin } \mathrm{T} \\
\text { slow skeletal muscle isoform } \mathrm{X} 1\end{array}$ & 32449.6 & 5.54 & 9 & 418 & $32 \%$ & $9.2 \mathrm{e}-03$ \\
\hline 1374 & gi|268607671 & actin, alpha skeletal muscle & 42366 & 5.23 & 11 & 348 & $35 \%$ & $9.2 \mathrm{e}-03$ \\
\hline
\end{tabular}

eNumber of times we would expect to obtain an equal or higher score by chance

membrane, cell, and cell part were prominently represented. For molecular functions, "catalytic activity" and "binding" represented the majority of the category.

To further evaluate the function of the unigenes, KOG classification of all the unigenes was performed, and
16,171 unigenes could be assigned to 25 categories (Fig. 5). Among the 25 KOG categories, the highest proportion of unigenes matched to "signal transduction mechanisms" (13.8\%), followed by cluster for "general function prediction only" (12.6\%), "post-translational

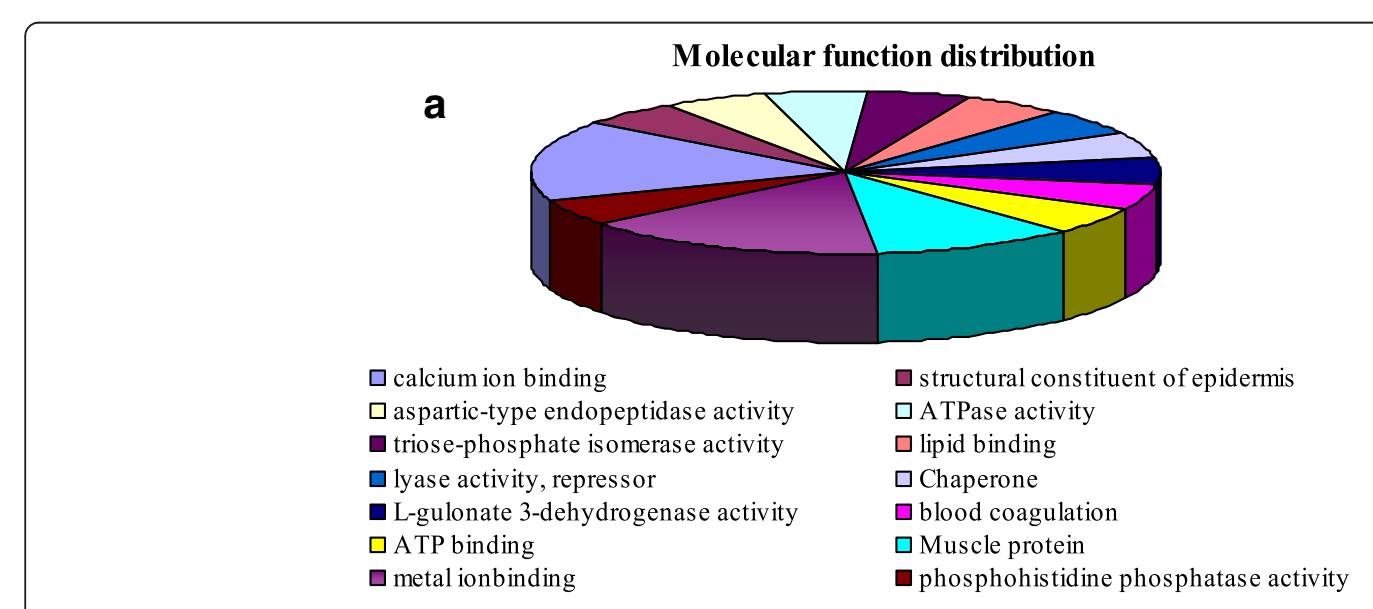

Biological process dis tribution

b

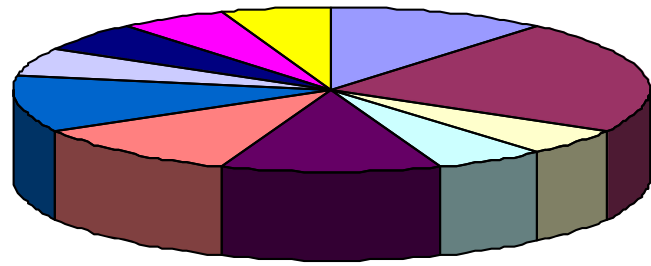

$\square$ skeletal muscle tis sue development

$\square$ cellular response to calcium ion

$\square$ muscle contraction

$\square$ digestion

$\square$ glycolytic process

$\square$ fatty acid metabolic process

$\square$ peptidyl-histidine dephosphorylation $\square$ transport

immune system process

$\square$ response to stress

Fig. $2 \mathrm{GO}$ annotation of different proteinic spots (a: molecular function distribution, b: Biological process distribution) 


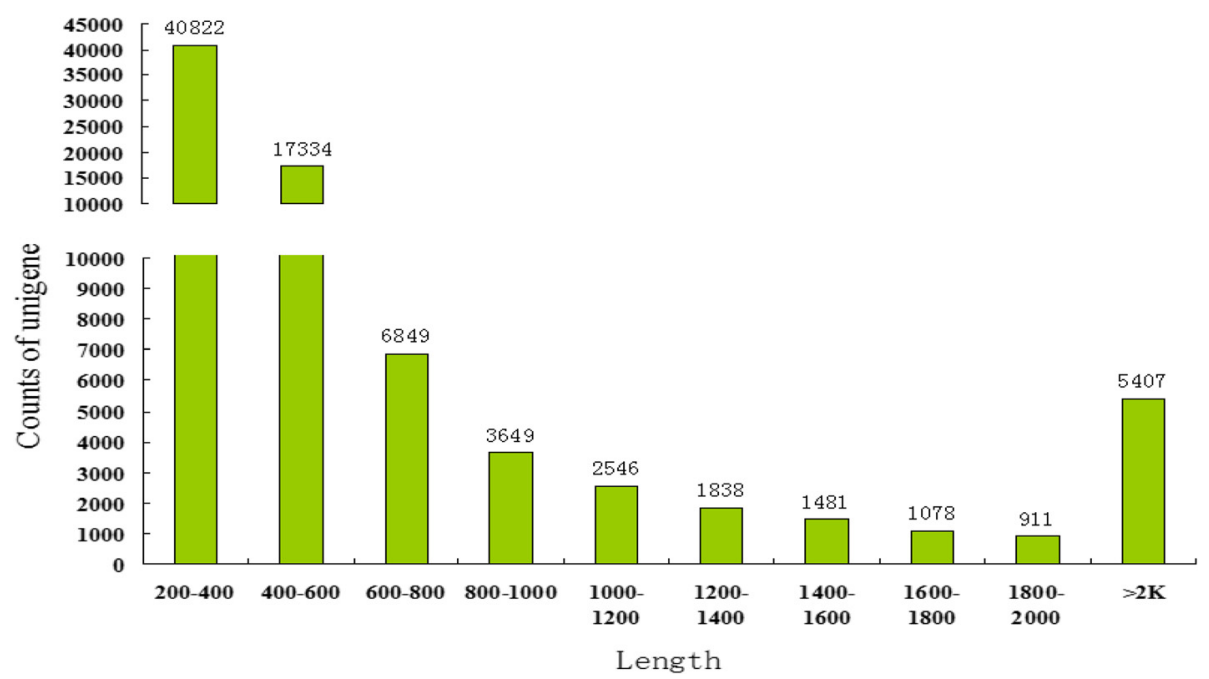

Fig. 3 Length distribution of the assembled final unigenes of Illumina sequences

modification, protein turnover, chaperones" (9.8 \%), and "carbohydrate transport and metabolism" (5.8\%). The KEGG pathway database is a powerful tool for the analysis of gene function in terms of gene networks [52]. To identify the biological pathways of transcriptome from the LM, all unigenes were submitted to KEGG pathway analysis. A total of 16,755 unigenes were assigned to 278 KEGG pathways (Additional file 1: Table S1), which fell into five main categories, including metabolism, environmental information processing, genetic information processing, cellular processes, and organism systems. Among the five main categories, the metabolism pathway represented the largest number of the unigenes (1013). These metabolic pathways were mainly carbohydrate metabolism, energy metabolism, amino acid metabolism, and lipid metabolism, which provided a valuable resource to investigate muscle growth and lipid metabolism processes.

\section{Identification and analysis of DEGs}

To identify the DEGs between the Shaziling and Yorkshire pigs, the relative expression of the genes was estimated using the RPKM value, which is a common method for estimating transcript levels [53]. According to the RNA-seq analysis, DEGs were selected using the criteria of FC $\geq 2$ and false discovery rate $\leq 0.05$; the FC distribution of DEGs is shown in Fig. 6. A total of 488 unigenes were identified

Table 3 Statistical summary of the longissimus dorsi muscle transcriptome for assembling

\begin{tabular}{llllll}
\hline Statistics & Counts & $\begin{array}{l}\text { Average } \\
\text { length (bp) }\end{array}$ & N50 (bp) & $\begin{array}{l}\text { Longest } \\
\text { length (bp) }\end{array}$ & $\begin{array}{l}\text { Total } \\
\text { length (bp) }\end{array}$ \\
\hline Contigs & 86,759 & 672 & 939 & 49,881 & $58,319,316$ \\
Scaffold & 81,915 & 713 & 1028 & 66,767 & $58,377,616$ \\
Unigenes & 79,320 & 733 & 1112 & 66,767 & $58,152,234$ \\
\hline
\end{tabular}

as DEGs between the two breeds, of which 297 were upregulated in the Shaziling pig and the 192 genes were upregulated in the Yorkshire pig. To better explore the functions of the DEGs, GO functional analysis was carried out. The results indicated that 488 DEGs were significantly enriched in $208 \mathrm{GO}$ categories (Additional file 2: Table S2). Notably, some of the categories are involved in the metabolic process and the regulation of skeletal muscle development.

\section{qPCR analysis}

To evaluate the proteomics and transcriptomics results, the expressions of eight genes were determined in the two pig breeds by qPCR on the basis of their different influence on the formation of meat flavor and skeletal muscle development. Four of the genes encoded proteins involved in glycolysis and fat deposition (ENO1, ENO3, $A T P 5 B$, and TPI1), three encoded proteins that correlated with synthesis of muscle fiber proteins (MYLPF, ACTA1, and $A C T C 1$ ) and the $H S P B 1$ gene, whose encoded protein plays a crucial role in maintaining cellular homeostasis [54] and protects against stress [23]. The fold-changes in expression of the eight genes were compared with the transcriptomics and proteomics analysis results. As shown in Fig. 7, the qPCR results revealed that five genes were in agreement with the RNA-Seq results and six genes

Table 4 Functional annotations using transcript BLAST analyses

\begin{tabular}{lll}
\hline Public database & Hit unigenes number & Percentage (hit/total) \% \\
\hline Annotated in $\mathrm{nr}$ & 23,055 & 29.07 \\
Annotated in UniProt & 25,784 & 32.50 \\
Annotated in GO & 23,702 & 29.8 \\
Annotated in KOG & 16,171 & 20.3 \\
Annotated in KEGG & 16,755 & 21.1 \\
\hline
\end{tabular}


showed a similar trend to proteomics results. In the present research, we also observed different expression trends between the proteomics and transcriptome analyses.

\section{Correlation analysis of mRNA and protein expression}

RNA-seq analyses identified 488 DEGs (Additional file 3: Table S3), of which 297 were upregulated in the Shaziling pig and 192 in the Yorkshire pig. Proteomics revealed identified 38 differentially abundant proteins, of which 27 protein spots were upregulated in the Shaziling pig and 11 in the Yorkshire pig. Similar to previous reports, the transcriptomics and proteomics data were divergent. In the present study, ENO1 and ACTC1 were overexpressed in Shaziling pigs, and ATP5B was overexpressed in Yorkshire pigs: only for these three genes were the proteomics results consistent with the transcriptomic results. In 2009, Timperio and colleagues performed a comparative analysis of proteomics and transcriptomics from the livers of Chianina and Holstein Friesian cattle. The results indicated that only three of 39 differentially abundant proteins were validated by microarray analyses [55]. Other research also confirmed that proteomics and transcriptomics data seldom overlap [56]. These differences were probably caused by alternative splicing, differential regulation of translation, and annotation errors of databases [57]. Another aspect concerning little overlap between transcriptomics and proteomics data is biological factors [58]. Although proteomics and transcriptomics data have almost no overlap, interaction pathway analyses could indicate shared biological significance [33]. Taking this into consideration, the differentially abundant proteins and DEGs that converged in the same metabolic pathways, especially regulation of skeletal muscle development, were meaningful. Some of the proteins and upregulated gene transcripts in Shaziling pigs were found to be involved in the same metabolic pathways, particularly the glycolytic pathway (ENO1, TPI1, and HSPB1). ENO1, a glycolytic enzyme, is positively correlated with meat tenderness [59]. TPI is also a glycolytic enzyme, and has been shown to correlate with meat tenderness in porcine muscles [60]. Notably, although the TPI1 result of proteomics and transcriptomics data did not match, pathway analyses of either DEG transcripts or proteins for the Shaziling samples were involved in a metabolic network. HSP proteins are related to protein folding and the oxidative stress response. In our research, HSPB1 was overexpressed in Shaziling pigs, and might be positively correlated with meat quality, which agreed with previous studies [61, 62]. Shaziling pigs have excellent meat quality like other Chinese indigenous pig breeds. The IMF content in Shaziling pigs is $3.5 \%$, in Jinhua pigs it is $3.38 \%$, and in Lantang pigs it is $2.46 \%$. By contrast, Yorkshire pigs and Landrace pigs have IMFs of $1.79 \%$ [7, 63]. Increased IMF content can improve meat quality significantly, especially in terms of tenderness [64]. According to our results, genes related to tenderness have a higher level of expression in Shaziling pigs than in Yorkshire pigs, for example TPI1, HSPB1, and ENO1. Further analysis of the DEGs identified a number of novel genes and pathways (Additional file 1: Tables S1, Additional file 2: Table S2

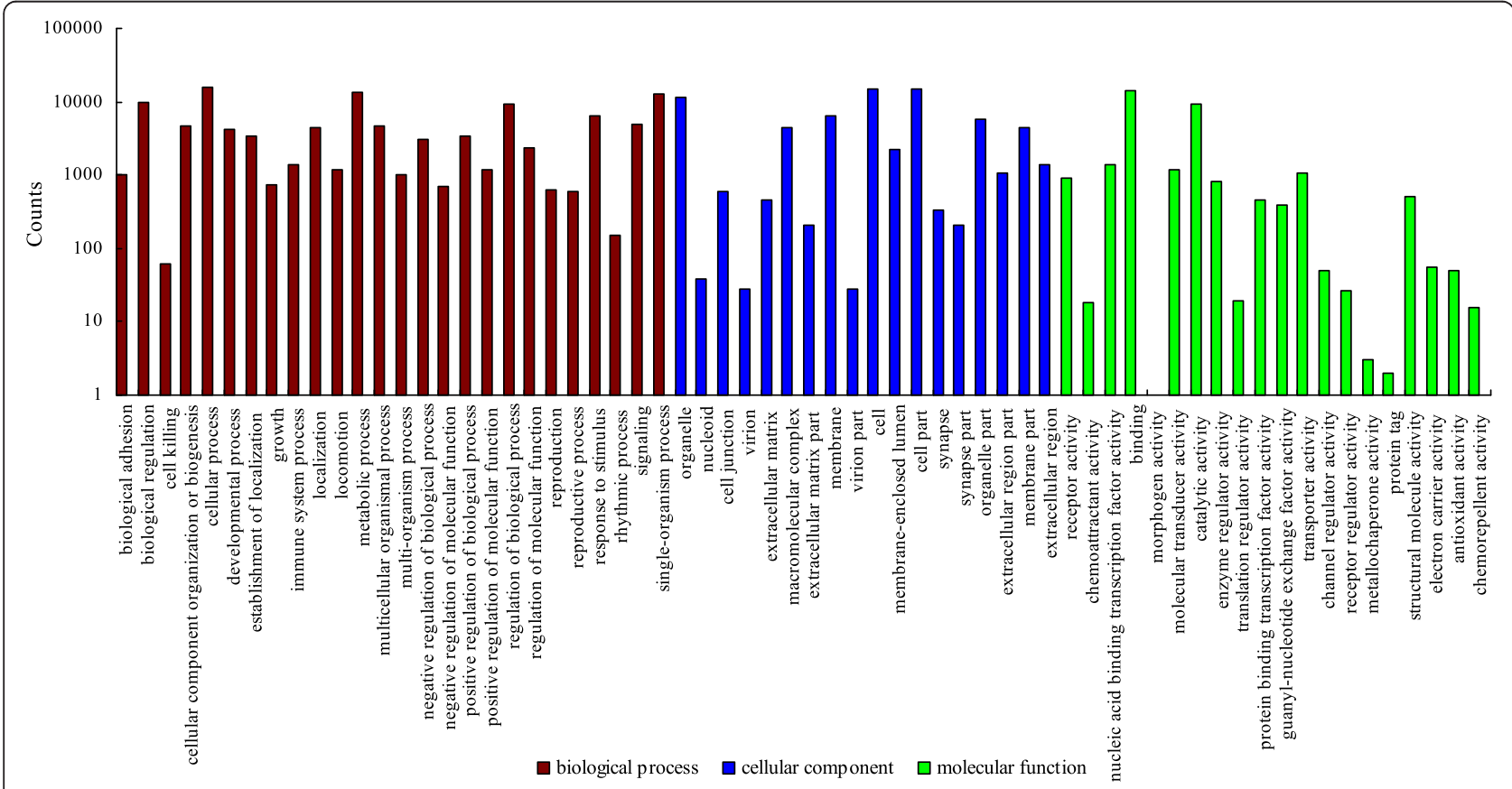

Fig. 4 Column chart presentation of GO classification of unigenes 

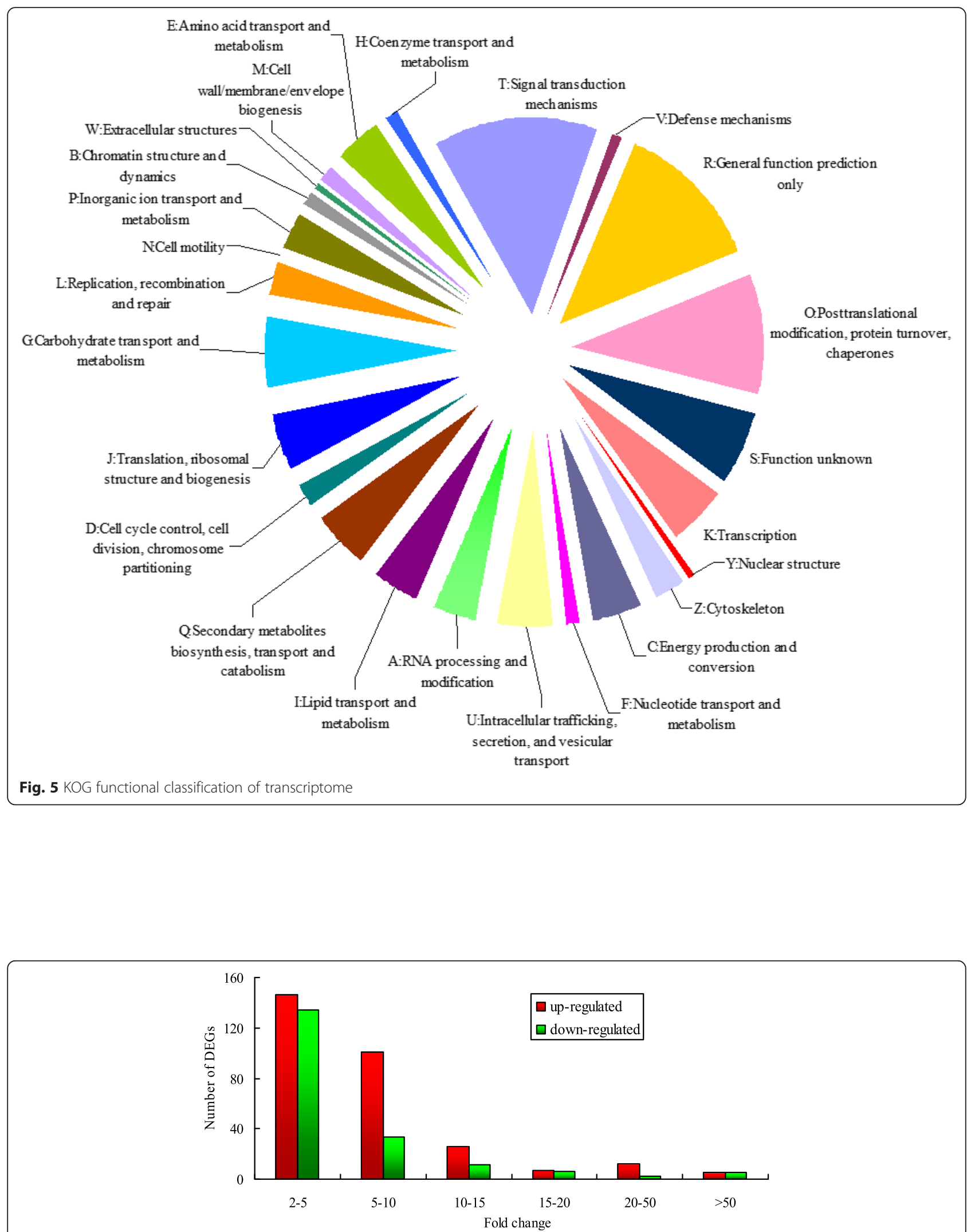

Fig. 6 The fold change distribution of up- and down-regulated DEGs. Green bars refer to down-regulated DEGs and red bars refer to up-regulated DEGs in Shaziling pigs compared with Yorkshire pigs. The $X$ axis shows fold change of DEGs and the $Y$ axis number of DEGs 


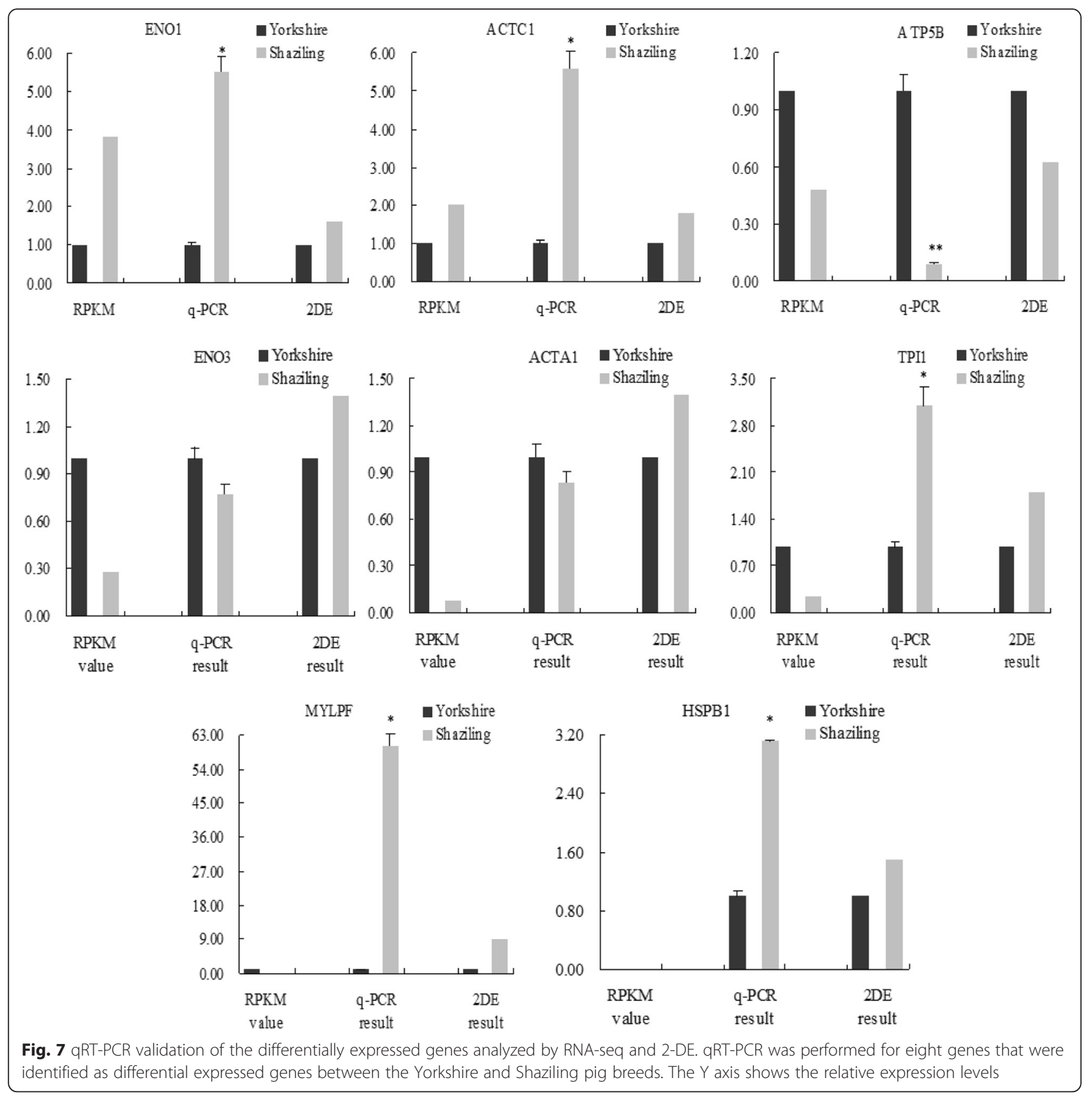

and Additional file 3: Table S3), which have not been reported to affect meat quality previously. Further characterization of these novel genes might reveal the regulatory mechanism underlying meat quality.

\section{Conclusion}

The object of this study was to investigate differences in the growth and development of skeletal muscle between Shaziling and Yorkshire pigs. The combined use of proteomic and transcriptomic analyses was effective in detecting DEGs and proteins. As a result, 38 differentially abundant proteins and 488 DEGs were identified by mass spectrometry and RNA-seq analysis, respectively. Some of the proteins and unigenes are associated with lipid metabolism or glycolytic metabolism, according to previously published results. Based on the putative results of GO term enrichment and KEGG pathway analyses, we determine that many of the differential abundant proteins and DEGs are related to lipid mobilization, energy metabolism, the cytoskeleton, and signal transduction. Our study provided valuable information that could contribute to a deeper understanding of the molecular mechanisms regulating the development and formation of skeletal muscle. 


\section{Additional files}

Additional file 1: Table S1. KEGG Pathway information of unigenes. (XLS 705 kb)

Additional file 2: Table S2. GO enrichment of DEG. (XLS $77 \mathrm{~kb}$ ) Additional file 3: Table S3. Summary of the differently expressed genes. (XLS $58 \mathrm{~kb}$ )

\section{Abbreviations}

2-DE, two-dimensional fluorescence difference gel electrophoresis; DEGs, differentially expressed genes; GO, gene ontology; IMF, intramuscular fat; KEGG, Kyoto Encyclopedia of Genes and Genomes; LM, longissimus dorsi muscle; MS, mass spectrometry; NGS, next-generation sequencing; qPCR, quantitative real-time PCR

\section{Acknowledgements}

We would like to thank LY for exceptional assistance in the qPCR and DX in collection of samples of pig tissue.

\section{Funding}

This study was supported by the National High Technology Research and Development Program of China (2011AA100304), the Provincial Natural Science Foundation of Hunan (13J 1021) and Science and technology project of hunan province (2014NK4135)

\section{Availability of data and materials}

The sequencing data from this study has been archived at the NCBI Sequence Read Archive under GEO database [GSE:70673]

\section{Authors' contributions}

HY performed analysis of the transcriptomics and proteomics and drafted the manuscript. XX and JJ participated in the biological experiments and data analysis. HM managed the whole project. All authors read and approved the final manuscript.

\section{Competing interests}

The authors declare that they have no competing interests.

\section{Consent for publication}

Not applicable.

\section{Ethics approval and consent to participate}

The experiment and all its procedures were reviewed and approved by the Institutional Animal Care and Use Committee (IACUC) at Hunan Agricultural University.

\section{Author details}

'College of Animal Science and Technology, Hunan Agricultural University, Changsha 410128, People's Republic of China. ${ }^{2}$ College of Life Science and Resource Environment, Yichun University, Yichun 336000, People's Republic of China.

\section{Received: 2 November 2015 Accepted: 2 June 2016}

\section{Published online: 13 June 2016}

\section{References}

1. Rosenvold $\mathrm{K}$, Andersen HJ. Factors of significance, for pork quality - a review. Meat Sci. 2003:64:219-37.

2. Megens HJ, Crooijmans RP, San Cristobal M, Hui X, Li N, Groenen MA. Biodiversity of pig breeds from China and Europe estimated from pooled DNA samples: differences in microsatellite variation between two areas of domestication. Gen Sel Evol. 2008;40(1):103-28.

3. Scherf BD. World watch list for animal diversity. 3rd ed. Rome: FAO; 2000.

4. Lefaucheur L. A second look into fibre typing - relation to meat quality. Meat Sci. 2010:84(2):257-70.

5. Xu YJ, Jin ML, Wang LJ, Zhang AD, Zuo B, Xu DQ, et al. Differential proteome analysis of porcine skeletal muscles between Meishan and Large White. J Anim Sci. 2009;87(8):2519-27.
6. Zhao SM, Ren $L$, Chen L, Zhang X, Cheng ML, Li WZ, et al. Differential expression of lipid metabolism related genes in porcine muscle tissue leading to different intramuscular fat deposition. Lipids. 2009;44(11):1029-37.

7. Wu T, Zhang Z, Yuan Z, Lo $\sqcup$, Chen J, Wang Y, et al. Distinctive genes determine different intramuscular fat and muscle fiber ratios of the longissimus dorsi muscles in Jinhua and landrace pigs. PLoS One. 2013;8(1):e53181.

8. Lu P, Li DF, Yin JD, Zhang LY, Wang ZY. Flavour differences of cooked longissimus muscle from Chinese indigenous pig breeds and hybrid pig breed (Durocx Landracex Large White). Food Chem. 2008;107(4):1529-37.

9. Liu X, Xiong X, Yang J, Zhou L, Yang B, Ai H, et al. Genome-wide association analyses for meat quality traits in Chinese Erhualian pigs and a Western Durocx(Landracex Yorkshire) commercial population. Genet Sel Evol. 2015; 47(1):44.

10. Guo J, Shan T, Wu T, Zhu LN, Ren Y, An S, et al. Comparisons of different muscle metabolic enzymes and muscle fiber types in Jinhua and Landrace pigs. J Anim Sci. 2011;89(1):185-91.

11. Kim NK, Joh JH, Park HR, Kim OH, Park BY, Lee CS. Differential expression profiling of the proteomes and their mRNAs in porcine white and red skeletal muscles. Proteomics. 2004:4(11):3422-8.

12. Guo Y, Li J, Shang J, Jin Y. Development of muscle-related genes and their effects on meat quality. Energy Procedia. 2012;16:229-33.

13. Picard B, Lefaucheur L, Berri C, Duclos MJ. Muscle fibre ontogenesis in farm animal species. Reprod Nutr Dev. 2002;42(5):415-31.

14. Zhao X, Mo D, Li A, Gong W, Xiao S, Zhang Y, et al. Comparative analyses by sequencing of transcriptomes during skeletal muscle development between pig breeds differing in muscle growth rate and fatness. PLoS One. 2011;6(5):e19774.

15. Karlsson AH, Klont RE, Fernandez X. Skeletal muscle fibres as factors for pork quality. Livest Prod Sci. 1999;60(2):255-69.

16. Wimmers K, Murani E, Ngu NT, Schellander K, Ponsuksili S. Structural and functional genomics to elucidate the genetic background of microstructural and biophysical muscle properties in the pig. J Anim Breed Genet. 2007; 124(1):27-34.

17. Quiroz-Rothe E, Rivero JL. Coordinated expression of myosin heavy chains, metabolic enzymes, and morphological features of porcine skeletal muscle fiber types. Micros Res Techniq. 2004;65(1-2):43-61.

18. da Costa N, McGillivray C, Chang KC. Postnatal myosin heavy chain isoforms in prenatal porcine skeletal muscles: insights into temporal regulation. Anat Rec Part A. 2003;273(2):731-40.

19. Lefaucheur L, Ecolan P, Plantard L, Gueguen N. New insights into muscle fiber types in the pig. J Histochem Cytochem. 2002;50(5):719-30.

20. Liu J, Damon M, Guitton N, Guisle I, Ecolan P, Vincent A, et al. Differentiallyexpressed genes in pig Longissimus muscles with contrasting levels of fat, as identified by combined transcriptomics, reverse transcription PCR, and proteomic analyses. J Agri Food Chem. 2009;57(9):3808-17.

21. Xu YJ, Qian H, Feng XT, Xiong YZ, Lei MG, Ren ZQ, et al. Differential proteome and transcriptome analysis of porcine skeletal muscle during debelopmemt. J Proteomics. 2012;75(7):2093-108.

22. Li A, Mo D, Zhao X, Jiang W, Cong P, He Z. Comparison of the longissimus muscle proteome between obese and lean pigs at 180 days. Mamm Genome. 2013;24(1-2):72-9.

23. Görg A, Weiss W, Dunn MJ. Current two dimensional electrophoresis technology for proteomics. Proteomics. 2004:4(12):3665-85.

24. Timms JF, Cramer R. Difference gel electrophoresis. Proteomics. 2008; 8(23-24):4886-97.

25. Lin CS, Hsu CW. Differentially transcribed genes in skeletal muscle of Duroc and Taoyuan pigs. J Anim Sci. 2005;83(9):2075-86.

26. Hollung K, Grove H, Færgestad EM, Sidhu MS, Berg P. Comparison of muscle proteome profiles in pure breeds of Norwegian Landrace and Duroc at three different ages. Meat Sci. 2009;81(3):487-92.

27. Kim NK, Lim JH, Song MJ, Kim QH, Park BY, Kim MJ, et al. Developmental proteomic profiling of porcine skeletal muscle during postnatal development. Asian Austral J Anim. 2007;20(10):1612-7.

28. Marguerat S, Bähler J. RNA-seq: from technology to biology. Cell Mol Life Sci. 2010;67(4):569-79.

29. Ramayo-Caldas Y, Mach N, Esteve-Codina A, Corominas J, Castello A Ballester $\mathrm{M}$, et al. Liver transcriptome profile in pigs with extreme phenotypes of intramuscular fatty acid composition. BMC Genomics. 2012 13(1):547.

30. Chen C, Ai H, Ren J, Li W, Li P, Qiao R, et al. A global view of porcine transcriptome in three tissues from a full-sib pair with extreme phenotypes 
in growth and fat deposition by pairedend RNA sequencing. BMC Genomics. 2011;12(1):448.

31. Tian Q, Stepaniants SB, Mao M, Weng L, Feetham MC, Doyle MJ. Integrated genomic and proteomic analyses of gene expression in mammalian cells. Mol Cell Proteomics. 2004;3(10):960-9.

32. Murgiano L, D'Alessandro A, Egidi MG, Crisa A, Prosperini G, Timpero AM, et al. Proteomics and transcriptomics investigation on longissimus muscles in Large White and Casertana pig breeds. J Proteome Res. 2010;9(12):6450-66.

33. Kim NK, Park HR, Lee HC, Yoon D, Son ES, Kim YS, et al. Comparative studies of skeletal muscle proteome and transcriptome profilings between pig breeds. Mamm Genome. 2010;21(5-6):307-19.

34. García-Alcalde F, Okonechnikov K, Carbonell J, Cruz LM, Götz S, Tarazona S, et al. Qualimap: evaluating next-generation sequencing alignment data. Bioinformatics. 2012;28(20):2678-9.

35. Wang $L$, Feng $Z$, Wang $X$, Wang $X$, Zhang $X$. DEGseq: an $R$ package for identifying differentially expressed genes from RNA-seq data. Bioinformatics. 2010;26(1):136-8.

36. Schmittgen TD, Livak KJ. Analyzing real-time PCR data by the comparative CT method. Nat Protoc. 2008;3(6):1101-8.

37. Orosz F, Oláh J, Ovádi J. Triosephosphate isomerase deficiency: new insights into an enigmatic disease. Biochim Biophys Acta. 2009:1792(12):1168-74.

38. Laville E, Sayd T, Terlouw C, Chambon C, Damon M, Larzul C, et al. Comparison of sarcoplasmic proteomes between two groups of pig muscles selected for shear force of cooked meat. J Agric Food Chem. 2007; 55(14):5834-41.

39. Farrar WW, Deal Jr WC. Purification and properties of pig liver and muscle enolases. J Protein Chem. 1995;14(6):487-97.

40. Kwasiborski A, Sayd T, Chambon C, Sante'-Lhoutellier V, Rocha D, Terlouw C. Pig Longissimus lumborum proteome: part II: relationships between protein content and meat quality. Meat Sci. 2008:80(4):982-96.

41. klont RE, Brocks I, Eikelenboom G. Muscle fibre type and meat quality. Meat Sci. 1998:49:s219-29.

42. Ryu YC, Kim BC. Comparison of histochemical characteristics in various pork groups categorized by postmortem metabolic rate and pork quality. J Anim Sci. 2006;84(4):894-901.

43. Helferich W, Jump DB, Anderson DB, Skjaerlund DM, Merkel RA, Bergen WG. Skeletal muscle alpha-actin synthesis is increased pretranslationally in pigs fed the phenethanolamine ractopamine. Endocrinology. 1990;126(6):3096-100.

44. Guillemin N, Bonnet M, Jurie C, Picard B. Functional analysis of beef tenderness. J Proteomics. 2011;75(2):352-65.

45. D'Alessandro A, Marrocco C, Zolla V, D'Andrea M, Zolla L. Meat quality of the longissimus lumborum muscle of Casertana and Large White pigs: metabolomics and proteomics intertwined. J Proteomics. 2011;75(2):610-27.

46. Huang X, Madan A. CAP3: a DNA sequence assembly program. Genome Res. 1999:9(9):868-77.

47. Wickramasinghe S, Cánovas A, Rincón G, Medrano JF. RNA-sequencing: a tool to explore new frontiers in animal genetics. Livest Sci. 2014;166:206-16.

48. Qian X, Ba Y, Zhuang Q, Zhong G. RNA-Seq technology and its application in fish transcriptomics. OMICS. 2014;18(2):98-110.

49. Gui D, Jia K, Xia J, Yang L, Chen J, Wu Y, et al. De novo assembly of the indo-pacific humpback dolphin leucocyte transcriptome to identify putative genes involved in the aquatic adaptation and immune response. PLoS One. 2013:8(8):e72417.

50. Ruan R, Guo AH, Hao YJ, Zheng JS, De WD. Novo assembly and characterization of narrow-ridged finless porpoise renal transcriptome and identification of candidate genes involved in osmoregulation. Int J Mol Sci. 2015;16(1):2220-38.

51. Conesa A, Gotz S, Garcia-Gomez JM, Terol J, Talon M, Robles M. Blast2GO: a universal tool for annotation, visualization and analysis in functional genomics research. Bioinformatics. 2005;21(18):3674-6.

52. Kanehisa M, Goto S, Sato Y, Furumichi M, Tanabe M. KEGG for integration and interpretation of large-scale molecular data sets. Nucleic Acids Res. 2011;40(Database issue):D109-14

53. Mortazavi A, Williams BA, McCue K, Schaeffer L, Wold B. Mapping and quantifying mammalian transcriptomes by RNA-Seq. Nat Methods. 2008:5:621-8.

54. Liu Y, Steinacker JM. Changes in skeletal muscle heat shock proteins: pathological significance. Front Biosci. 2001;6:D12-25.

55. Timperio AM, D'Alessandro A, Pariset L, D'Amici GM, Valentini A, Zolla L. Comparative proteomics and transcriptomics analyses of livers from two different Bos taurus breeds: "Chianina and Holstein Friesian". J Proteomics. 2009;73(7):309-22.
56. Nie L, Wu G, Culley DE, Schotten JCM, Zhang W. Integrative analysis of transcriptomic and proteomic data: challenges, solutions and applications. Crit Rev Biotechnol. 2007;27(2):63-75

57. Hornshøj H, Bendixen E, Conley LN, Andersen PK, Hedegaard J, Panitz F. Transcriptomic and proteomic profiling of two porcine tissues using highthroughput technologies. BMC Genomics. 2009;10(1):30.

58. Samulin J, Berget I, Lien S, Sundvold H. Differential gene expression of fatty acid binding proteins during porcine adipogenesis. Comp Biochem Physiol B: Biochem Mol Biol. 2008;151(2):147-52.

59. D'Alessandroa A, Rinalduccia S, Marroccoa C, Zollaa V, Napolitanob F, Zollaa L. Love me tender: an Omics window on the bovine meat tenderness network. J Proteomics. 2012;75(2):4360-80.

60. Hwang IH, Park BY, Kim JH, Cho SH, Lee JM. Assessment of postmortem proteolysis by gel-based proteome analysis and its relationship to meat quality traits in pig longissimus. Meat Sci. 2005:69(1):79-91.

61. Bouley J, Meunier B, Chambon C, De Smet S, Hocquette JF, Picard B. Proteomic analysis of bovine skeletal muscle hypertrophy. Proteomics. 2005; 2:490-500.

62. Morzel M, Terlouw C, Chambon C, Micol D, Picard B. Muscle proteome and meat eating qualities of Longissimus thoracis of "Blonde d' Aquitaine" young bulls: a central role of HSP27 isoforms. Meat Sci. 2008;78:297-304.

63. Yu K, Shu G, Yuan F, Zhu X, Gao P, Wang S, et al. Fatty acid and transcriptome profiling of longissimus dorsi muscles between pig breeds differing in meat quality. Int J Biol Sci. 2013;9(1):108-18.

64. Van Laack R, Stevens S, Stalder K. The influence of ultimate pH and intramuscular fat content on pork tenderness and tenderization. Anim Sci. 2001;79:392-7.

\section{Submit your next manuscript to BioMed Central and we will help you at every step:}

- We accept pre-submission inquiries

- Our selector tool helps you to find the most relevant journal

- We provide round the clock customer support

- Convenient online submission

- Thorough peer review

- Inclusion in PubMed and all major indexing services

- Maximum visibility for your research

Submit your manuscript at www.biomedcentral.com/submit
) Biomed Central 